\title{
Surface Texturing of Vitamin E Blended UHMWPE for Reduction of Wear
}

\author{
B. SAGBAS ${ }^{a, *}$ And M.N. DurakBasA ${ }^{b}$ \\ ${ }^{a}$ Department of Mechanical Engineering, Yildiz Technical University, 34349 Besiktas, Istanbul, Turkey \\ ${ }^{b}$ Department of Interchangeable Manufacturing and Industrial Metrology, Institute for Production Engineering \\ and Laser Technology, Vienna University of Technology, Karlspl. 13/3113, A-1040 Wien, Austria
}

Ultra high molecular weight polyethylene (UHMWPE) has been the most commonly used bearing material in artificial hip and knee replacements. But wear and wear debris of UHMWPE has been the most important problem which cause aseptic loosening and revision surgery of these replacements. For enhangement of wear resistance, new generation UHMWPE materials have been developed and different surface modification techniques have been tried. The objective of this study is to determine the effect of surface dimples on wear behavior of conventional UHMWPE and vitamin E blended UHMWPE (VE-UHMWPE) in ultra-pure water lubrication conditions. Pin-on-disc tribotester was used for measurement of friction coefficient and wear. $0.5 \mathrm{~mm}$ in diameter dimples were machined on the surfaces of UHMWPE and VE-UHMWPE discs. CoCrMo pins were used as counter surface. Results were evaluated in terms of materials and presence of dimples.

DOI: 10.12693 /APhysPolA.125.481

PACS: 87.85.J-

\section{Introduction}

In artificial hip and knee joint arthroplasty, ultrahigh molecular weight polyethylene (UHMWPE) has been the most preferred prosthesis material with its excellent biocompatibility, mechanical properties and chemical stability $[1,2]$. But wear of UHMWPE is still most restrictive factor for implant service life. The wear debris of UHMWPE induces adverse tissue reactions, aseptic loosening and implant lost [3]. For enhancement of wear resistance, new generation of UHMWPE materials have been developed. Addition of $\alpha$-tocopherol or vitamin $\mathrm{E}$ as a natural antioxidant, into UHMWPE has been introduced as one way for improving material properties $[4,5]$. Vitamin $\mathrm{E}$ stabilizes the residual free radicals in the structure and increases oxidation and delamination resistance of conventional and cross-linked UHMWPE while maintaining the mechanical properties $[6-9]$. To improve lubrication and enhance wear resistance, different surface modification techniques have been tried.

One of the well known modification technique is surface patterning of artificial joint materials for reducing friction and wear [10]. Young et al. [11] reported that surface patterning reduced the frictional coefficient of conventional UHMWPE disc samples. But wear factor increased by surface patterning. They concluded that surface patterns were plastically deformed by high contact pressure so they lost their efficiency. In another study Nishimura et al. [12] tried surface patterning in different dimensions and they concluded that wear could be decreased by machining $0.5 \mathrm{~mm}$ in diameter surface dimples on conventional UHMWPE.

*corresponding author; e-mail: bsagbas@gmail.com
Although researches have been done about surface patterning of UHMWPE, there is no consensus about dimensions of dimples and it is not clear if surface patterning decreases or increases wear of UHMWPE. Actually there is no study about surface patterning of vitamin $E$ blended UHMWPE (VE-UHMWPE). The objective of this study is to determine the effect of surface dimples on wear behavior of conventional UHMWPE and VE-UHMWPE in ultrapure water lubrication conditions.

\section{Materials and methods}

UHMWPE and VE-UHMWPE disc samples were machined from Chirulen 1020 and Chirulen $1020 \mathrm{E}$ rods (MediTECH Medical Polymers, Vreden, Germany) in $40 \mathrm{~mm}$ diameter and $5 \mathrm{~mm}$ thickness in accordance with ASTM G99-05 [13]. CoCrMo pin samples were used as counter face. One group of sample surfaces were left as machined, $0.5 \mathrm{~mm}$ in diameter surface dimples were machined on the other samples surfaces by computer numerical control milling machine. The depth of the dimple was $0.5 \mathrm{~mm}$ and the distance between the center points of the dimples was $2 \mathrm{~mm}$. Surface roughness of the samples was measured by Taylor Hobson Form Talysurf Intra. Surface roughness of UHMWPE was $0.678 \mu \mathrm{m}$, of VE-UHMWPE was $0.653 \mu \mathrm{m}$. CAD/CAM model and manufactured disc sample can be seen in Fig. 1.

Pin-on-disc tribotester was used for wear analysis and friction coefficient measurements. $35 \mathrm{~N}$ static load was applied with the frequency of motion $1 \mathrm{~Hz}$ and the tests were run up to $3 \mathrm{~h}$. The tests were conducted in ultrapure water lubrication conditions. Wear track profile area was measured by Dektak 6 M Stylus Profiler for determining wear amount of the disc surfaces (Fig. 2). After wear tests the worn surfaces were analyzed by Keyence VHX Digital Microscope. 

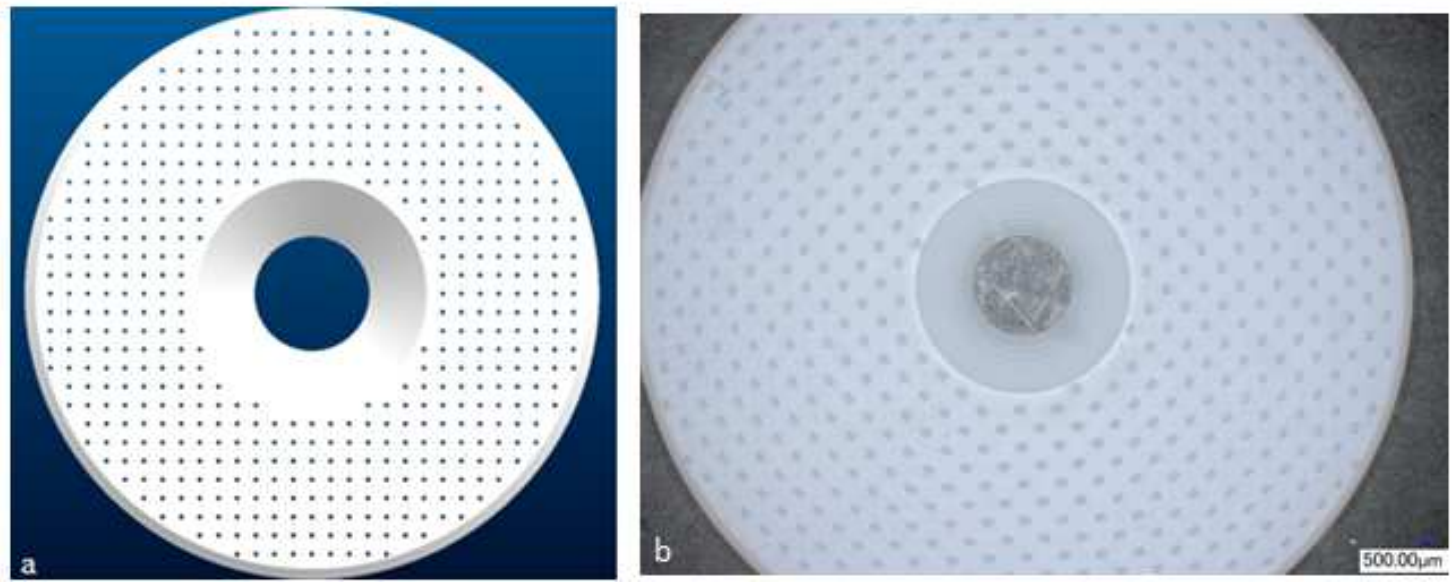

Fig. 1. (a) CAD model of the disc with surface dimples, (b) machined disc sample.

By using cross-sectional area of wear track and its radius the wear volume was calculated. Then by using Eq. (1) wear factor $(k)$ of each disc sample was determined

$$
k=\frac{V}{N S} .
$$

$k$ - wear factor $\left(\mathrm{mm}^{3} /(\mathrm{N} \mathrm{m})\right), V$ - wear volume $\left(\mathrm{mm}^{3}\right)$, $N$ - applied load (N), $S$ - friction distance (m) [14, 15].
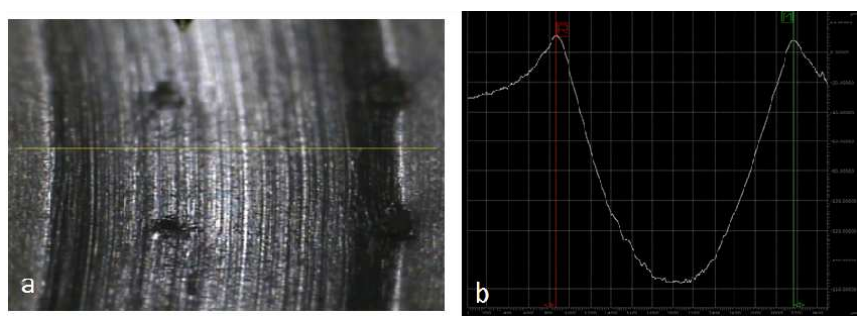

Fig. 2. (a) Worn surface (a), wear track profile (b).

\section{Results and discussion}

Pin-on-disc wear tests results, such as friction coefficient and wear track area can be seen in Fig. 3a and b. The measured wear track profile areas of unpatterned and patterned conventional UHMWPE were $0.1207 \mathrm{~mm}^{2}$ and $0.1038 \mathrm{~mm}^{2}$, respectively. For VE-UHMWPE these values became $0.0903 \mathrm{~mm}^{2}$ and $0.0505 \mathrm{~mm}^{2}$ for unpatterned and patterned samples, respectively. Wear factor $k$ for unpatterned UHMWPE was $4.54 \times$ $10^{-5} \mathrm{~mm}^{3} /(\mathrm{N} \mathrm{m})$, for patterned UHMWPE was $2.75 \times$ $10^{-5} \mathrm{~mm}^{3} /(\mathrm{N} \mathrm{m})$, for unpatterned VE-UHMWPE was $3.38 \times 10^{-5} \mathrm{~mm}^{3} /(\mathrm{N} \mathrm{m})$ and for patterned VE-UHMWPE was $1.34 \times 10^{-5} \mathrm{~mm}^{3} /(\mathrm{N} \mathrm{m})$. Friction coefficient, wear track profile area and wear factor of the VE-UHMWPE samples were lower than for conventional UHMWPE. Surface patterning reduced the frictional coefficient and wear factor of both material samples. Surface dimples acted as reservoir for lubricant and provide better lubrication condition for sliding surfaces. So friction coefficient of the materials decreased. Likely, with better lubrication wear amount of disc surface was decreased, too.

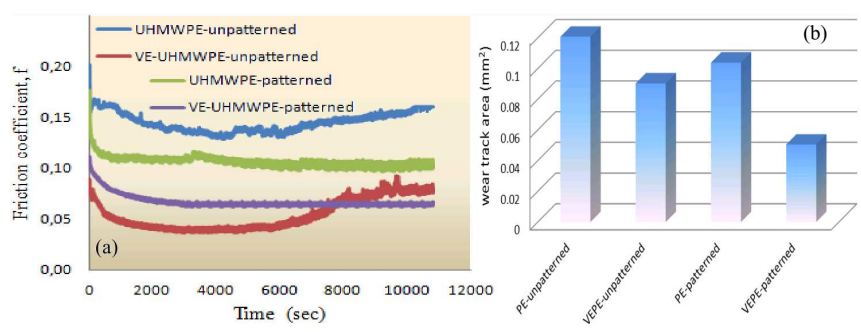

Fig. 3. (a) Friction coefficient of unpatterned and patterned discs, (b) average wear track area of the discs.

Microscopic images of the worn surfaces can be seen in Fig. 4. Wear factor of conventional UHMWPE was higher than VE-UHMWPE. Sakoda et al. [16] studied about wear behavior of conventional UHMWPE and VE-UHMWPE knee prosthesis by using knee simulator. They concluded that wear of VE-UHMWPE was $30 \%$ lower than of conventional UHMWPE. Vitamin E served to decrease oxidation of UHMWPE and decreased lamination and formation of surface cracks. So friction coefficient and wear factor of VE blended UHMWPE decreased.

It can be seen in Fig. 4 that surface dimples shapes plastically deformed under high contact pressure at the end of the tests. So the dimples might lose their efficiency on improving lubrication condition. For preserving dimples form under high loading and long working hours, the dimensions of the dimples must be optimized and the properties of the surfaces must be characterized by high precision metrological devices [17]. Surface dimples with different radius and depth must be tested under different experimental conditions. Our experiments are going on in this direction. 


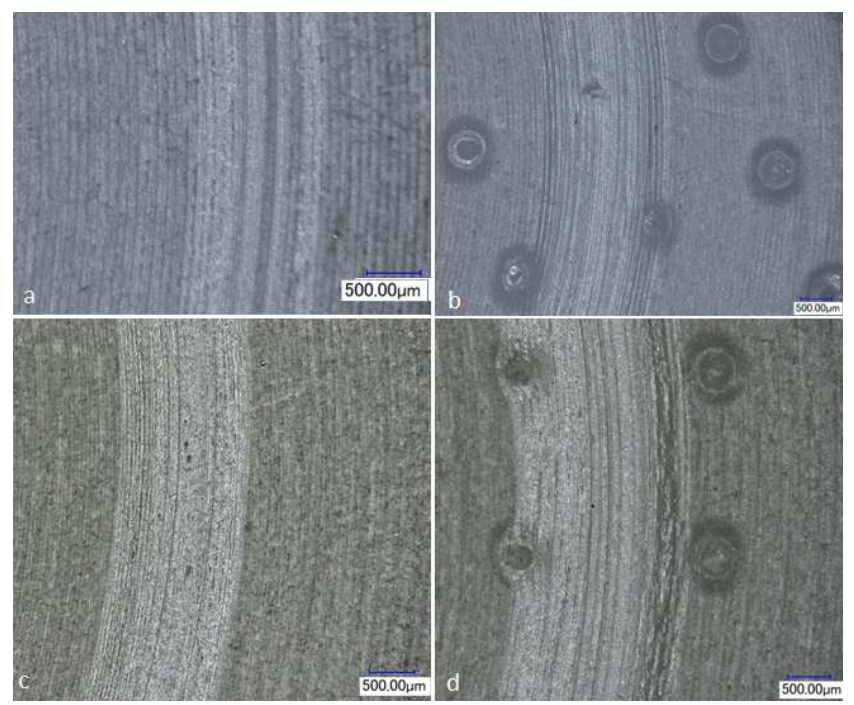

Fig. 4. Digital microscope images of worn surfaces: (a) unpatterned UHMWPE, (b) patterned UHMWPE, (c) unpatterned VE-UHMWPE, (d) patterned VE-UHMWPE.

\section{Conclusion}

Surface texture plays an important role for the efficient interactions as well as for enhancing the tribological properties of surfaces, including surface affinities and chemical reactions. In this study it was aimed to determine the effect of surface dimples on wear behavior of conventional UHMWPE and VE-UHMWPE in ultrapure water lubrication conditions. Surface dimples were machined on disc samples and pin-on-disc wear tests were conducted. The results showed that $0.5 \mathrm{~mm}$ in diameter surface dimples decreased the frictional coefficient and wear factor of both conventional UHMWPE and VE-UHMWPE disc samples. Surface dimples acted as reservoir for lubricant and provide better lubrication condition for sliding surfaces. So friction coefficient and wear of the materials decreased.

\section{Acknowledgments}

This research has been supported by Yildiz Technical University Scientific Research Projects Coordination Department. Project number: 2011-06-01-DOP03.
The authors would like to thank to the Department for Interchangeable Manufacturing and Industrial Metrology and Nanometrology Laboratory at the Vienna University of Technology, Wien, Austria, for support of surface measurements and to MediTECH Medical Polymers (Vreden, Germany) for material support of the study.

\section{References}

[1] H. Bhatt, T. Goswami, Biomed. Mater. 3, 1 (2008).

[2] D. Xiong, S. Ge, Wear 250, 242 (2011).

[3] H. Minakawa, M.H. Stone, B.M. Wroblewski, J.G. Lancaster, E. Ingham, J. Fisher, J. Bone Joint Surg. Brit. Vol. 80, 894 (1998).

[4] F. Renò, M. Cannas, Biomaterials 27, 3039 (2006).

[5] C. Vaidya, E. Alvarez, J. Vinciguerra, D.A. Bruce, J.D. DesJardins, Proc. Institut. Mech. Eng. Part H J. Eng. Med. 225, 1 (2011).

[6] P. Bracco, E. Oral, Clin. Orthop. Relat. Res. 469, 2286 (2011).

[7] E. Oral, S.L. Rowell, O.K. Muratoglu, Biomaterials 27, 5580 (2006).

[8] E. Oral, K.K. Wannomae, N.E. Hawkins, W.H. Harris, O.K. Muratoglu, Biomaterials 25, 5515 (2004).

[9] E. Oral, S.D. Christensen, A.S. Malhi, K.K. Wannomae, O.K. Muratoglu, J. Arthropl. 21, 580 (2006).

[10] T.G. Mathia, P. Pawlus, M. Wieczorowski, Wear 271, 494 (2011).

[11] S.K Young, M.A Lotito, T.S Keller, Wear 222, 29 (1998).

[12] I. Nishimura, T. Yuhta, K. Ikubo, T. Shimooka, S. Murabayashi, Y. Mitamura, ASAIO J. 39, 762 (1993).

[13] ASTM G99-05(2010), Standard Test Method for Wear Testing with a Pin-on-Disk Apparatus.

[14] L. Ma, V.M. Rainforth, D. Sun, J.A. Wharton, R.J.K. Wood, Wear 267, 2122 (2009).

[15] T. Pylios, D.E.T. Shepherd, Inc. J. Biomed. Mater. Res. Part B Appl. Biomater. 84B, 520 (2008).

[16] S. Teramura, H. Sakoda, T. Terao, M.M. Endo, K. Fujiwara, N. Tomita, J. Orthop. Res. 26, 460 (2008).

[17] M.N. Durakbasa, P.H. Osanna, Acad. J. Manufact. Eng. 1, 6 (2003). 